\title{
El acceso a Internet como derecho fundamental: perspectivas internacionales
}

\section{The access to Internet as a fundamental right: international perspectives}

\author{
Ángel Carmelo Prince Torres ${ }^{1}$
}

\begin{abstract}
RESUMEN
El siguiente artículo tiene como propósito analizar el acceso a Internet como potencial derecho fundamental (derecho humano) in statu nascendi, a raíz de opiniones y debates en la comunidad internacional y la ley en algunos de sus Estados miembros. Esta investigación es de naturaleza teórica cualitativa con diseño documental y versa sobre Derecho Internacional Público, se apoya en diferentes posturas doctrinales, constitucionales, legales y judiciales sobre el tema, para estudiar si el acceso a Internet es considerado como un interés protegido del derecho positivo en un contexto interestatal, por lo cual se diferencia a través del método comparado la cobertura que a este respecto se ha tenido en contraste con las fuentes jurídicas internas de distintos países .La conclusión fue que el acceso a Internet tiene las características de un derecho beneficia a las personas, debido a que algunos Estados tienen sistemas jurídicos que reconocen la protección de esta prerrogativa y al mismo tiempo, ha habido debates en la Organización de las Naciones Unidas acerca de la importancia de esta herramienta como medio para ejercer otros derechos reconocidos al ser humano.
\end{abstract}

Palabras claves: Internet, derecho fundamental, Estados, comunidad internacional.

\begin{abstract}
This article has the purpose to analyze the access to internet as a potential fundamental right (human right) in statu nascendi, following opinions and discussions of the international community and the law in some of its member States. This qualitative, theoretical and documented research of Public International Law is supported by doctrine and different constitutional, legal and judicial postures about this topic, pursuing to study if the internet access can be considered as a protected interest of the positive interstate law comparing the coverage of this topic by legal sources in different countries. The conclusion was that the internet access has the characteristics of a right that should benefit people, because some States have legal systems which recognize the protection of this prerogative and at the same time, there have been debates in the United Nations, about the importance of this tool as a way to achieve other rights recognized to human beings.
\end{abstract}

Keywords: Internet, fundamental right, States, international community.

\footnotetext{
Abogado y profesor en educación comercial egresado de la Universidad Fermín Toro y el Instituto Universitario Pedagógico «Monseñor Rafael Arias Blanco» respectivamente (Venezuela). Magister en Derecho Administrativo y Tributario así como Máster Universitario en Derecho Internacional por la Universidad Complutense de Madrid (España). Doctor en Ciencias de la Educación (Universidad Fermín Toro, Venezuela). Excoordinador de postgrado de la Universidad Fermín Toro, exdecano de la Facultad de Ciencias Jurídicas y Políticas de la Universidad Yacambú, docente de pregrado y postgrado de la Universidad Fermín Toro, Universidad Centroccidental Lisandro Alvarado e Instituto Universitario Pedagógico Monseñor Rafael Arias Blanco (Venezuela). Barquisimeto, República Bolivariana de Venezuela. Correo: arbqto@gmail.com
} 


\section{Introducción}

Los derechos humanos son aceptados en el mundo jurídico como una serie de prerrogativas que han sido reconocidas y plasmadas de forma escrita en la esfera normativa, son innatas de las personas y en función del surgimiento de amenazas distintas, pueden enriquecerse de acuerdo al marco de protección que se desea implantar de forma positiva, a manera de escudo para contener el detrimento de todos aquellos elementos que son indispensables tanto material como inmaterialmente, en aras de que hombres, mujeres, adolescentes y nińos puedan lograr un desarrollo pleno de integridad tanto psíquica, como física y moral. Así «todos tenemos los mismos derechos humanos, sin discriminación alguna. Estos derechos son interrelacionados, interdependientes e indivisibles» ${ }^{2}$

No resulta extraño sostener que existe eventual crecimiento del catálogo de derechos humanos con el propósito de satisfacer necesidades de las personas cuya protección habría sido impensable en épocas pasadas. Como ejemplos se tienen a los derechos al agua potable y al saneamiento, que en el siglo XXI han sido reconocidos por la Organización de Naciones Unidas como conformantes del núcleo de derechos fundamentales para los seres humanos, a través de una resolución formal de su Asamblea General. ${ }^{3}$

Incluso al referirse a la formulación escrita de la norma en el marco del Derecho Internacional, existen pronunciamientos doctrinales, tales como aquellos que sostienen que «es aspiración de todo sistema jurídico sustituir la costumbre por Derecho escrito(...) la lenta e incierta elaboración de reglas a través de prácticas acompañadas de una convicción de necesidad social y obligatoriedad jurídica (...) adecuado a las circunstancias cambiantes del tiempo histórico $» .{ }^{4}$ Con esto se sustenta lo expuesto en anteriores líneas: el Derecho es de naturaleza dinámica y por lo tanto, las normas referidas a los derechos humanos también lo son al discutir los derechos civiles y políticos, económicos, sociales y culturales, ambientales, indígenas $\mathrm{y}$ en general los de cuarta generación que a futuro se proyecten.

Ahora bien, es conocido el hecho de que actualmente se vive dentro del espectro de la globalización, la internacionalización y la era de la informática. Por ello tal y como acentúa Pedro de miguel asensio (refiriendo a E. Trigueros en su obra «Trayectoria del Derecho Mundial») «la interconexión mundial implica que determinados cambios tengan un alcance global (...) lo que determina que cada Estado por separado no se encuentre en una posición idónea para proceder a su regulación. Manifestaciones claras de la necesidad de una especial coordinación entre autoridades de diversos Estados (...) pueden encontrarse en sectores $\tan$ diversos como (...) el funcionamiento de internet.» ${ }^{5}$

Internet se constituiría en función de la acentuación anterior, en una herramienta con impacto global en los ámbitos político, económico, social, e incluso jurídico, por lo que no resulta descabellado estudiar su composición en tanto comporta un instrumento informático que se ha implicado en hechos decisivos para la humanidad. Es precisamente por ello que algunos gobiernos han bloqueado su acceso, siendo casos emblemáticos los de la ley francesa Hadopi (Haute autorité pour la diffusion des oeuvres et la protection des droits sur Internet), las restricciones del gobierno chino sobre sitios web como facebook, twitter, youtube, linkedln, llegando incluso a crear un buscador específico para rechazar palabras determinadas (como democracia, por ejemplo), también las medidas de Egipto de limitación al acceso de Internet durante los sucesos que provocaron la caída del régimen de Hosni Mubarak, o incluso podrían señalarse las acciones

\footnotetext{
Organización de Naciones Unidas - Oficina del Alto Comisionado para los Derechos Humanos (s.f.) 1.

Resolución A/RES/64/292 de 2010.

Calatayud Et al. (2007) p.523.

De Miguel Et al (2001) pp.37 - 87.
} 
del gobierno iraní, fomentando el aislamiento web sobre sitios que han propugnado levantamientos por impulso de activistas determinados. ${ }^{6}$

Resulta importante que en el marco del análisis realizado con respecto al acceso a Internet y sus implicaciones en el mundo de los derechos fundamentales, se destaque la elaboración de un informe en el año 2011 fechado con el día 16 de mayo, titulado Report of the Special Rapporteur on the Promotion and Protection of the Right of Freedom of Opinion and Expression y redactado por el relator especial de la Organización de Naciones Unidas, Frank La Rue. ${ }^{7}$ En él se expone la importancia del acceso a Internet para la práctica de derechos humanos como la libertad de expresión y opinión en el siglo XXI.

A raíz del informe La Rue, se ha afirmado en diferentes canales de información que la Asamblea General de la Organización de Naciones Unidas (que en lo sucesivo de este artículo se denominará como ONU) ha declarado a Internet como un derecho humano, llegando incluso a ser respaldada esta aseveración por importantes medios de comunicación como CNN. ${ }^{8}$ Sin embargo cabría preguntarse si es irrefutable la consideración del acceso a Internet como un derecho natural, es decir, ¿existe pronunciamiento vinculante de la ONU con respecto a esto aparte del informe La Rue? Así dicha cuestión fue aquí analizada.

Los Estados igualmente en su afán por contar dentro de su sistema jurídico con herramientas que le permitan afrontar los retos generados en el avance de este siglo, han procurado enriquecer sus normas para considerar la protección de Internet como un planteamiento de gran importancia. Como ejemplo de este fenómeno se tiene a Finlandia, que como país consultado por la Organización para la Seguridad y la Cooperación en Europa (OSCE), cuenta con medidas concretas para dar protección a la internet en cuanto, por solo nombrar uno, el aspecto de la neutralidad garantizada e igualmente concibe a Internet como un derecho fundamental de sus ciudadanos. ${ }^{9}$

A fin de cuentas, para establecer la caracterización de la herramienta informática como un medio de consecución de los fines básicos de derechos fundamentales, debe dejarse en primer lugar muy claro que cuando hablamos de "derechos humanos", hay un acuerdo general en que nos referimos a un conjunto de derechos que nos corresponden a todos, sin ningún tipo de excepción, solo por el hecho de pertenecer a la gran familia humana. ${ }^{10}$ Es aquí precisamente en donde se encontraría el asidero para desglosar los puntos referidos a la utilización de medios electrónicos como forma de replicación de la acción de esas prerrogativas naturales, pues se plantearía la cuestión de si el uso de Internet es determinante para el desarrollo de la humanidad actualmente y si resulta una barrera para este logro la capacidad que tenga el Estado en cubrir esta necesidad. De allí cabe cuestionar si realmente Internet ha sido declarado como un derecho humano por la ONU.

Por todo lo ya apuntado, surgen las siguientes preguntas: ¿¿Resulta de utilidad para el estudio del Derecho Internacional en el marco de los Derechos Fundamentales analizar los alcances del acceso a Internet como derecho humano? ¿Cuáles son las características de Internet como medio comunicacional en el mundo globalizado? ¿Existe una relación de interdependencia y conexidad de ciertos derechos humanos en el marco de la utilización de Internet en el corriente siglo XXI? ¿Cuál es el asidero normativo y

\footnotetext{
El Mundo (2011) p.1.

La Rue (2011) p.1.

CNN (2011) p.1.

Akdeniz (2012) p.35.

10 Amnistía Internacional (s.f) 1. La connotación positiva que se da a la importancia de la creciente discusión sobre los problemas referidos a los derechos humanos en Bobbio, Norberto. El Tiempo de los Derechos y en este sentido, la acepción de que los derechos fundamentales se desarrollan en un contexto histórico según Fioravanti Los Derechos Fundamentales.
} 
jurisprudencial referido a internet que puede observarse en el contexto de los miembros de la comunidad internacional, para su consideración como un derecho efectivamente tutelado y básico? Y por último, ¿es clara la postura de la ONU sobre la consideración del acceso a Internet como un derecho humano en su incorporación al catálogo de derechos fundamentales?

Todas las interrogantes que se han mencionado, representan el punto de inicio para estudiar al acceso a Internet como un derecho humano. Así este trabajo tiene como propósito general analizar el acceso a Internet como un Derecho Fundamental en el marco del Derecho Internacional Público. Por otra parte, los propósitos específicos de este escrito son: 1. Señalar las características de Internet como medio comunicacional en el contexto del mundo globalizado; 2. Observar antecedentes jurisprudenciales de los miembros de la comunidad internacional, referidos al acceso a Internet como un Derecho Humano; 3. Exponer la legislación de algunos Estados miembros de la comunidad internacional, en cuanto a la consideración del acceso a Internet como derecho tutelado; y 4. Evaluar informes técnicos jurídicos que vinculan el acceso a Internet con los Derechos Humanos.

Resulta pertinente indicar que este artículo refiere a perspectivas internacionales, pues parte de una investigación con diseño documental desarrollada bajo enfoque cualitativo, ya que se analiza el fenómeno de la discusión sobre la naturaleza de potencial derecho humano que tiene el acceso a Internet en el contexto del Derecho Internacional Público de los Derechos Humanos. ${ }^{11}$ Es pues esta una obra teórica y doctrinal, que aunque se sirve del Derecho Comparado y menciona jurisprudencia para contrastar el marco internacional con la formalidad que ya existe internamente en algunos Estados que aceptan a Internet como un derecho humano, versa sobre la tímida postura que ha tenido la comunidad internacional al no asumir aún en 2020 instrumentos jurídicos obligatorios sobre ello, sino que más bien han gestado acuerdos no vinculantes y recomendaciones que se desdoblan más adelante en este texto.

Para la consecución de los objetivos aquí planteados se ha estructurado el trabajo estableciendo los aspectos generales de los derechos humanos, de forma que toda aquella persona no jurista interesada en el tema escogido y los estudiantes de derecho o abogados que aún no conozcan la materia en profundidad, puedan comprenden los conceptos y el alcance del contenido subsiguiente. Posteriormente se procede a desglosar los aspectos más relevantes sobre Internet, con especial énfasis en antecedentes históricos que constituyen el punto de partida para la comprensión del estudio, esgrimiendo los fundamentos teóricos y el sustento jurídico que soportan este artículo (incluidos jurisprudencia, doctrina, normas positivas nacionales e informes y acuerdos soft law ${ }^{12}$ de Derecho Internacional Público). Para finalizar se realizan las reflexiones sobre la obligatoriedad de considerar Internet como derecho humano en el plano interestatal y la correcta o incorrecta apreciación que sobre ello se tiene a raíz de la información recabada. Todo este cuerpo se ha diseñado sobre la base del método deductivo: procesos de pensamiento que parten de lo general a lo particular.

\footnotetext{
11 «El derecho internacional de los derechos humanos establece las obligaciones que los Estados deben respetar. Al pasar a ser partes en los tratados internacionales, los Estados asumen las obligaciones y los deberes, en virtud del derecho internacional, de respetar, proteger y realizar los derechos humanos». Organización de Naciones Unidas - Oficina del Alto Comisionado para los Derechos Humanos (s.f.) 1. Sin embargo, existen también herramientas jurídicas internacionales no vinculantes que colaboran con la comprensión y desenvolvimiento del derecho internacional de los derechos humanos tales como los informes recomendatorios y declaraciones de soft law que representan el punto álgido de este trabajo.

12 "El soft law hace referencia a reglas de conducta que en principio no tienen fuerza jurídica vinculante, aunque produzcan efectos prácticos " Baldassare (2017) p.1.
} 


\section{Derechos Humanos: generalidades}

Para definir a los derechos fundamentales, resulta conveniente aclarar que para los efectos de este escrito se han utilizado como sinónimos los términos derechos humanos y derechos naturales, pues resulta conveniente para el propósito de dar un enfoque global sobre las acepciones que la doctrina sostiene en este campo. Al respecto puede decirse que «bastante agua ha corrido bajo el puente desde que los hombres empezaron a preguntarse por los derechos humanos. Tomándolos como sinónimos de los derechos naturales, Jeremy Bentham afirmaba hace más de dos siglos que aquellos no eran sino un disparate en zanco (...) ". ${ }^{13}$ Sin embargo, a pesar del extracto antes expuesto con el que puede evidenciarse la sinonimia terminológica indicada, no debe negarse que la esencia de ese núcleo de derechos viene dado por su carácter trascendental en el tiempo.

Los Derechos Humanos pueden definirse así: «(...) son el reconocimiento de lo que es propio del ser humano dentro de la vida social. Los derechos fundamentales son tales por ser derechos humanos. Y los derechos fundamentales son el núcleo del mundo jurídico y la primera categoría por la que existe interdependencia inexcusable entre justicia y derecho». ${ }^{14}$ Se observa por ello que la condición de estos elementos no es más que la búsqueda de protección a las personas por su propia cualidad, en el entendido de que lo ideal es que tales cuestiones se contemplen por la ley conjuntamente con un sistema de garantías reforzadas por los tratados internacionales, el derecho consuetudinario, los principios estructurales del derecho internacional y con otras fuentes de esta vertiente jurídica. ${ }^{15}$

\section{Características de los derechos fundamentales}

Para comprender de forma más profunda la esencia de los derechos naturales, es necesario que se explique la caracterización que tienen los mismos:

1. Iguales y no discriminatorios, pues esta característica es directriz transversal en el Derecho Internacional de los Derechos Humanos ya que se encuentra recogida en todos los tratados de derechos humanos y es el punto álgido en convenciones internacionales como la Convención Internacional sobre la Eliminación de todas las Formas de Discriminación Racial (1965, con entrada en vigor para 1969) ${ }^{16}$ o la Convención sobre la Eliminación de todas las Formas de Discriminación contra la Mujer (1979, con entrada en vigor para 1981). ${ }^{17}$

2. Comportan propiamente derechos, pero también deberes de Derecho Internacional.

3. Universalidad, pues los derechos humanos deben ser protegidos por los Estados.

4. Circunscripción a protección con compromiso internacional de defensa erga omnes.

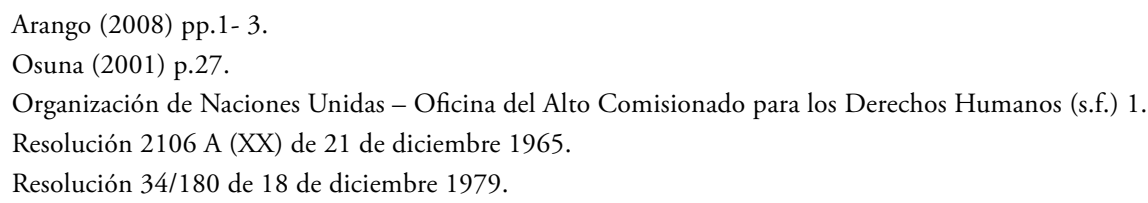


5. En el marco internacional, la consideración de la persona y su dignidad como un elemento guía y autónomo de la sociedad internacional que por esta razón, se transforma en un bien jurídico protegible por el Derecho Internacional. ${ }^{18}$

6. La progresividad porque al ser reconocidos, no pueden retraerse de manera alguna.

7. Son supratemporales: se enlazan con el ser humano y están por encima del tiempo y del Estado.

8. Indivisibilidad e interdependencia, y sobre este punto se expone desde la Organización de Naciones Unidas que «todos los derechos humanos (...) son derechos indivisibles, interrelacionados e interdependientes. El avance de uno facilita el avance de los demás». ${ }^{19}$

Los derechos fundamentales deben ser promocionados y respetados. Por ello entrañan el deber de denuncia de discriminaciones en las cuales incurra el Estado, así como las instituciones y los procedimientos que se encarguen de esto. También debe aclararse que los derechos civiles y políticos tienen para los Estados compromisos de resultado, mientras que los económicos, sociales y culturales, son de desarrollo progresivo atendiendo a las condiciones económicas y sociales de los países. En cuanto a los derechos de tercera generación, que son «de solidaridad» o «derechos colectivos o de los pueblos», en la esfera universal es proclamada su dimensión humana en instrumentos no convencionales. ${ }^{20}$

Una vez desglosados los aspectos anteriores tiene que acotarse que los derechos fundamentales deben ser conocidos en cuanto a sus elementos más resaltantes, de manera que pueda visualizarse si ese derecho de acceso a Internet del cual se habla actualmente, reúne al menos los requisitos más relevantes para haber sido considerado por expertos e incluso marcos legislativos, como un interés susceptible de ser protegido. Por ello no resulta extrańo que el uso de Internet represente uno de los indicadores sobre el avance de los Estados, siendo que a este respecto «de acuerdo con un informe publicado por la Unión Internacional de Telecomunicaciones (UIT), el acceso a la Internet, y particularmente a la banda ancha fija, da idea del grado de desarrollo de los países, mejor que la tradicional medición basada en la telefonía ${ }^{21}$ y así habiendo partido de este supuesto, pueden mencionarse las siguientes utilidades de Internet: a) Es un medio de comunicación no tradicional b) es un canal de distribución difícil de controlar c) es una herramienta para el entretenimiento e) aparte de todo internet representa un importante mecanismo para manifestar la libertad de expresión e igualmente para la información.

\section{Internet y derechos humanos}

Internet, tal como se refiere cuando se ha indagado sobre el derecho a la información, ${ }^{22}$ es un instrumento que en un principio no tuvo implicaciones de carácter mercantil, sino que fue un proyecto de investigación del Departamento de Defensa de los Estados Unidos de Norteamérica en el año 1969, en vista que $A R P A n e^{23}$ unía sitios universitarios, empresariales y estatales en una red informática que fue ampliada por

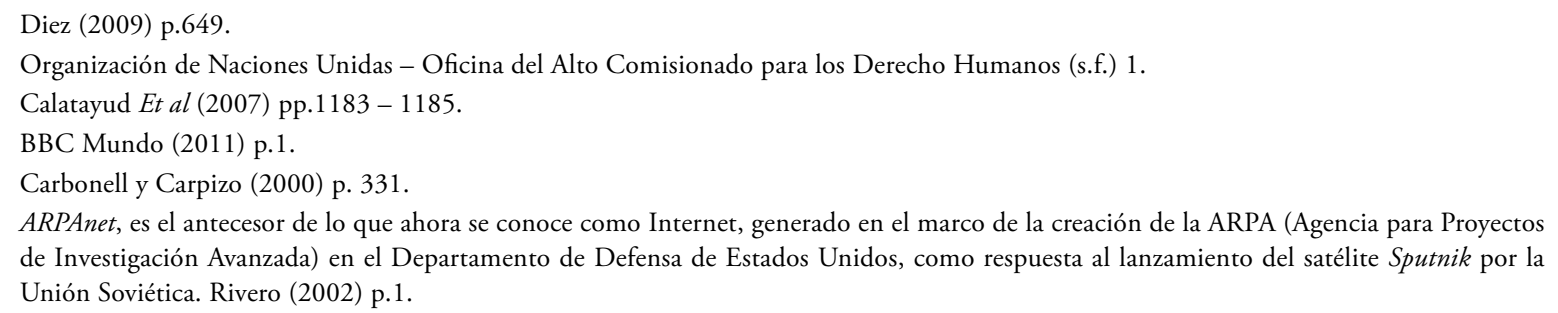


la National Science Foundation (NSFNET) para fines de investigación, hasta llegar a las manos privadas. Ya en 1990 en el Centro Europeo de Investigación Nuclear de Ginebra se gestaron los protocolos de conexión e hipertexto de interfaz gráfica de la World Wide Web y en 1993 se conoció el primer buscador web (Mosaic) por cuenta del National Center for Supercomputing Applications (NCSA). Así de forma gradual evolucionó el alcance de Internet como herramienta para el fomento de la globalización con ahorro de tiempo y dinero.

Progresivamente en cuanto a los derechos e Internet, surgen propuestas como la de Robert B. Gelman, quien para el año 1997 sugiere una Declaración de los Derechos Humanos en el ciberespacio, cuyo fundamento se sostuvo con los principios rectores de la Declaración Universal de los Derechos Humanos de las Naciones Unidas. Se alude en ella a novedosas vertientes de las prerrogativas existentes en el mundo on-line y expone derechos basados en las vías para la libertad de asociación e información (como las comunidades virtuales, redes sociales, entre otros), de la información, la condición humana, la libertad, la paz, la justicia, el derecho inalienable a la libertad de expresión, el derecho a la educación en la era globalizada, así como el derecho a la conexión por redes telemáticas. ${ }^{24}$

De esta forma, se llega posteriormente al desarrollo jurisprudencial y normativo de los derechos reconocidos en el marco de la implementación de Internet, con decisiones judiciales en países como Francia o Costa Rica, así como la implementación de normas legales y constitucionales protectoras o promotoras de Internet en países como Estonia, Finlandia y Grecia. Esto por nombrar solo algunos casos de territorios en los cuales se ha llegado a sostener que la prenombrada herramienta representa un servicio de obligatoria prestación estatal y se ha identificado propiamente como un derecho fundamental.

Sobre el acceso a Internet, a continuación se apuntan tres (3) sentencias ${ }^{25}$ que ratifican su carácter esencial para la esfera de los ciudadanos. En el caso conocido como de la Ley HADOPI del año 2009, el Consejo Constitucional de Francia con la decisión denominada como Décision n²009-580 DC du 10 juin 2009, Conseil constitutionnel, Loi favorisant la diffusion et la protection de la création sur Internet, considera que el acceso al servicio de Internet se encuentra subsumido en el derecho a la libertad de expresión, que a su vez se deriva directamente de la Declaración Universal de los Derechos del Hombre del año 1789. De esta manera el Consejo Constitucional francés, estima que los servicios de prestación de Internet (implícitos en los de comunicación) comportan no solo un elemento de carácter generalizado, sino que también son canales de participación en la vida democrática, la expresión de ideas y de opiniones, por lo cual su acceso debe ser facilitado.

Así, explica el Consejo que los poderes de sanción de la Haute Autorité pour la diffusion des oeuvres et la protection des droits sur Internet (que contemplaban en este caso la posibilidad de suspender, restringir o impedir el acceso a Internet por suscripción), al ser extensivos a toda la población, implicaban la restricción en el ejercicio de los derechos de comunicarse y expresarse con libertad. ${ }^{26}$ Por esto conviene comprender de forma más clara el alcance de la exposición del Consejo Constitucional francés, al apuntar que el artículo 11 de la Declaración de 1789 establece que: «La libre comunicación de los pensamientos y de las opiniones es uno de los derechos más preciados del hombre; todo ciudadano puede, por tanto, hablar,

\footnotetext{
4 Ortega (2004) pp. 678, 679.

25 No es propósito de este artículo realizar un examen exhaustivo de estas sentencias, sino tomarlas como antecedentes jurisprudenciales por haber sido mencionadas en los informes de Naciones Unidas analizados más adelante en este trabajo.

26 Consejo Constitucional de Francia (18.06.2009).
} 
escribir e imprimir libremente, salvo la responsabilidad que el abuso de esta libertad produzca en los casos determinados por la ley». ${ }^{27}$

No resulta descabellado afirmar que el Consejo Constitucional sencillamente asumió la adaptación del contenido en el precitado artículo para hacerlo aplicable al corriente siglo XXI y su encuadre a las utilidades de la tecnología, la cual actualmente permite libertad de comunicación y pensamiento. Luego al seguir el hilo de este tipo de pronunciamientos judiciales, conviene mencionar que la Sala Constitucional de la Corte Suprema de Justicia de Costa Rica al decidir recurso de amparo contra el Instituto Costarricense de Electricidad (ICE) el 18 de junio de 2010, en cuanto a la prestación de servicio de Internet ha expresado:

«En este caso concreto, por el servicio público en cuestión -el servicio de telecomunicaciones- también están involucrados otros dos derechos fundamentales, el derecho a la comunicación y el derecho a la información (...) si bien son derechos relacionados con otros, tales como la libertad de expresión (...) estos derechos tienen su particularidad propia. Asimismo, aunque se perfilan más claramente en la actualidad, tienen sus raíces en la Declaración Universal de los Derechos Humanos (...) cuando señala en su artículo 19 que "todo individuo tiene derecho a la libertad de opinión y de expresión; este derecho incluye el de no ser molestado a causa de sus opiniones, el de investigar y recibir informaciones y opiniones, y el de difundirlas, sin limitación de fronteras, por cualquier medio de expresión" y en la Convención Americana sobre Derechos Humanos, promulgada en el año 1969 (Pacto de San José), cuando indica que la libertad de pensamiento y expresión comprenden " (...) la libertad de buscar, recibir y difundir información e ideas(...).” En este sentido, todas las entidades encargadas del servicio público de telecomunicaciones están en la obligación de respetar dichos derechos, claro está, una vez cumplidos los requisitos establecidos (...) En este caso el ICE está obligado a prestar el servicio de Internet». ${ }^{28}$

Se observa así en la decisión revisada que la prestación de los servicios públicos en Costa Rica debería conforme al órgano jurisdiccional, ser considerada como eficiente y no solo esto sino obligatoria para la materialización de otros derechos fundamentales. También destacable es el hecho de que más directo resulta el pronunciamiento que con posterioridad emitió la misma Sala Constitucional en el caso de recurrentes contra el Ministerio de Ambiente, Energía y Telecomunicaciones, Ministerio de la Presidencia sobre recurso de amparo en 30 de julio de 2010 acerca del acceso a Internet, en el cual lo califica como un derecho fundamental con el siguiente argumento:

«El avance en los últimos veinte años en materia de tecnologías de la información y comunicación (TIC) ha revolucionado el entorno social del ser humano (...) En este momento, el acceso a estas tecnologías se convierte en un instrumento básico para facilitar el ejercicio de derechos fundamentales como la participación democrática (democracia electrónica) y el control ciudadano, la educación, la libertad de expresión y pensamiento, el acceso a la información y los servicios públicos en línea, el derecho a relacionarse con los poderes públicos por medios electrónicos y la transparencia administrativa, entre otros. Incluso, se ha afirmado el carácter de derecho fundamental que reviste el acceso a estas tecnologias, concretamente, el derecho de acceso a la Internet o red de redes. En tal sentido, el Consejo Constitucional de la República francesa, en la sentencia No. 2009-580 DC de 10 de junio de 2009, reputó como un derecho básico el acceso a Internet, al desprenderlo, directamente, del artículo 11 de la Declaración de los Derechos del Hombre y del Ciudadano de 1789» ${ }^{29}$

\footnotetext{
7 Declaración de los Derechos del Hombre y del Ciudadano de 1789.

28 Corte Suprema de Justicia de Costa Rica (18.06.2010).

29 Corte Suprema de Justicia de Costa Rica (30.07.2010).
} 
En la sentencia anterior se observa en la ratio decidendi como se asume la postura de que Internet es un derecho humano pues así lo manifiesta la corte de forma directa. Todo esto compone un corolario de decisiones que ayudan a sustentar la afirmación de que el acceso a Internet, bien sea como un elemento subsumido en un servicio, o bien por su propia naturaleza y papel fundamental dentro de la sociedad de la información tan vigente ahora en el año 2020, es considerado en sede judicial como un potencial derecho humano instrumental para la realización de otros.

\section{Relación de los derechos conectados con Internet}

El acceso a Internet se encuentra vinculado a derechos fundamentales que son una manifestación directa de la aspiración al respeto de la dignidad humana y por ello, debe hacerse mención a los principales derechos que por el principio de interdependencia se encuentran interconectados a la red de redes:

1. Libertad de expresión: La libertad de expresión de forma global, trata sobre el «(...) derecho de todos a manifestar y comunicar sin trabas el propio pensamiento(...)» 30

$\mathrm{Al}$ respecto se expone en el Pacto Internacional de Derechos Civiles y Políticos (artículo 19) ${ }^{31}$ lo siguiente: «Toda persona tiene derecho a la libertad de expresión; este derecho comprende la libertad de buscar, recibir y difundir informaciones e ideas de toda índole (...)»

Igualmente, se contempla tal acepción (en concatenación con el Derecho a la Información) en instrumentos jurídicos internacionales regionales como por ejemplo la Convención Americana de Derechos Humanos, la cual establece en su artículo 13 que «toda persona tiene derecho a la libertad de pensamiento y de expresión». ${ }^{32}$ También indica el Convenio para la Protección de los Derechos Humanos y las Libertades Fundamentales (Convenio Europeo de Derechos Humanos) ${ }^{33}$ en su artículo 10 que «toda persona tiene derecho a la libertad de expresión. Este derecho comprende la libertad de opinión y la libertad de recibir o de comunicar informaciones o ideas sin que pueda haber injerencia de autoridades públicas y sin consideración de fronteras». De esta forma se observa que el derecho a la libertad de expresión, junto con el derecho a la libertad de información, se encuentran perfectamente consolidados en textos jurídicos universales y regionales de carácter internacional, a fin de garantizar su protección.

1. Derecho a la libertad de información: Este derecho entraña el libre flujo de información (emisión, recepción), así como la libertad en la comunicación, aparte que debe dejarse muy claro que por ello no tendría que confundirse con el derecho a la libertad de expresión, pues este versa sobre opiniones. ${ }^{34}$

2. Derecho a la igualdad: La igualdad, «(...) hace referencia a la existencia en dos o más personas o cosas de un mismo rasgo o elemento desde el cual se establece la comparación entre ellas» ${ }^{35}$ y de esta manera entrańa dos dimensiones: a) La necesidad de un trato rigurosamente paritario, sin tomar en cuenta

\footnotetext{
$30 \quad$ Aguado y Aragón (2011) p.197.

Resolución 2200 A (XXI) de 16 de diciembre 1966.

Convención Americana sobre Derechos Humanos de 22 de noviembre de 1969.

Convenio para la Protección de los Derechos Humanos y las Libertades Fundamentales de 4 de septiembre 1950.

$\mathrm{Al}$ respecto, se sostiene que la veracidad de un acontecimiento, puede probarse en tanto que se tome en cuenta: a) El hecho de atenderse al sentido global de la información, descontando aspectos no relevantes b) La pericia profesional de quien emana la información c) el traslado de declaraciones de un tercero sin comentarios d) La consideración de que el medio será un transmisor de la información. Cámara et al (2008) $189-192$.

35 Aguado y Aragón (2011) p.133.
} 
diferencias entre las personas y b) la adecuación a las condiciones de cada sujeto, procurando un trato de iguales entre iguales.

3. También en el marco jurídico internacional regional, se apunta en la Convención Americana de Derechos Humanos, artículo 24, que «todas las personas son iguales ante la ley. En consecuencia, tienen derecho, sin discriminación, a igual protección de la ley» ${ }^{36}$ y con ello se observa que por el principio de igualdad se defiende la paridad (que también se recoge en el artículo 1 de la Declaración Universal de Derechos Humanos, aunque abarcando un ámbito universal).

4. Derecho al libre desenvolvimiento de la personalidad: ha estimado el Tribunal Constitucional de Perú respecto a la demanda de inconstitucionalidad de la Asociación de Comerciantes de San Ramón y Figari contra Municipalidad distrital de Miraflores en 22 de junio de 2007 que «el libre desenvolvimiento de la personalidad constituye un derecho fundamental innominado o implícito que se deriva o funda en el principio fundamental de dignidad de la persona... En efecto, la valoración de la persona como centro del Estado y de la sociedad, como ser moral con capacidad de autodeterminación, implica que deba estarle también garantizado la libre manifestación de tal capacidad.... ${ }^{37}$

Así el derecho al libre desenvolvimiento de la personalidad, se constituiría como una forma de manifestación de la noción propiamente dicha de la libertad del individuo. Ahora bien, no implica lo expuesto en este punto que son exclusivamente estos derechos los que se concatenan con el acceso a internet, pues el desarrollo de un derecho fundamental condiciona el avance de otros. Luego, con el propósito de observar que efectivamente el acceso a internet se ha convertido en un bien jurídico protegido en los últimos años, se visualiza igualmente que su tutela se ha diversificado en el campo legislativo e incluso en el campo constitucional, estableciendo su naturaleza de derecho básico. En Estonia, por ejemplo, con la implementación en el año 2000 de la Telecommunications Act, ${ }^{38}$ se agrega el acceso a Internet a la lista de servicios universales de telecomunicaciones. Por su parte, Finlandia en 2003 establece la Telecommunications $A c t,{ }^{39}$ con la que se concibió un servicio universal dentro del cual se incluye una conexión funcional a Internet para los usuarios.

Muy importante resulta en este marco mencionar que Grecia, ya con rango constitucional, abraza directamente al acceso a la información electrónica (desarrollada por Internet) como un derecho fundamental en la esfera de los Derechos Sociales e Individuales. De esta manera, al insertarse el artículo $5 \mathrm{~A}^{40}$ en el texto constitucional griego se estipuló que el derecho a la información es considerado como blindado, con excepción del resguardo legal en razón de seguridad nacional, combate del crimen o protección e intereses de terceros. También es resaltante el hecho de que se concibe que todos están legitimados para participar en la sociedad de la información de la cual tanto se habla actualmente, siendo considerada como obligación del Estado la facilitación de acceso a información electrónica en sus dimensiones de producción, intercambio y difusión, con resguardo de las garantías de protección electrónica de datos personales y el secreto de comunicaciones (artículos 9A y 19 de la Constitución griega, respectivamente).

\footnotetext{
Convención Americana de Derechos Humanos de 22 de noviembre de 1969.

Asociación de Comerciantes de San Ramón y Figari con Municipalidad distrital de Miraflores (2007).

Telecommunications Act de 9 de febrero 2000.

Act. 393/2003 de 2003.

«1. Todos tienen derecho a la información, tal y como se detalle por ley. Las restricciones a este derecho pueden solamente imponerse por ley y en la medida en que sean absolutamente necesarias y justificadas por razones de seguridad nacional, lucha contra el crimen o protección de derechos o intereses de terceros.

2. Todos tienen derecho a participar en la Sociedad de la Información. El Estado está obligado a facilitar el acceso a la información transmitida electrónicamente, así como a su producción, intercambio y difusión, siembre salvaguardando las garantías establecidas en los artículos 9, 9A y 19 ». Constitución de la República de Grecia de 9 de junio de 1975, con enmienda en 1986, 2001, 2008 y 2019.
} 
Es con soporte en estos marcos normativos, que puede afirmarse que «el acceso a Internet representa hoy por hoy, un interés que es jurídicamente tutelado por ciertos Estados y ya ha sido acoplado a sus ordenamientos jurídicos internos». Sin embargo, a pesar de que en este apartado se mencionaron derechos conexos a la red de redes, ninguno de los tratados internacionales que los contemplan asume el acceso a Internet propia y específicamente como derecho humano, a pesar que tal cuestión ha sido recomendada una y otra vez por expertos de diferentes organizaciones y organismos internacionales en la última década.

\section{Informe referido al derecho de acceso a Internet en el seno de la organización de Naciones Unidas: reporte especial sobre la promoción y protección del derecho a la libertad de opinión y expresión del año 2011}

Gran revuelo causó en decenas de prestigiosos medios de comunicación a nivel mundial durante el año 2011, la noticia de que el derecho de acceso a internet había sido ya declarado como un derecho humano por la Asamblea General de Naciones Unidas. La fundamentación para esta postura se encontró en un informe emanado en el seno de la organización internacional, referido a la libertad de expresión y de opinión con especial referencia a Internet. Teniendo en cuenta tal documento ¿cabe afirmar que efectivamente el derecho humano a Internet ha sido reconocido plenamente en un plano jurídico internacional, creando una vinculación por tal motivo para los Estados en cuanto a cumplir las obligaciones allí impuestas? Y para resolver tal duda, debe desglosarse en primer lugar el carácter de los informes de los relatores especiales de Naciones Unidas en la esfera supraestatal.

Hay mecanismos estatuidos fuera del ámbito de los tratados por órganos de la Organización de Naciones Unidas, que pueden ser concretos con respecto a algunos Estados u obedecer a índices temáticos, dándoseles el nombre de mecanismos extraconvencionales (refiriendo al trabajo de los relatores especiales o expertos independientes). Los relatores, están bajo nombramiento de la Comisión de Derechos Humanos y la Subcomisión de Prevención de Discriminaciones y Protección de las Minorías, los grupos de trabajo de estos órganos y representantes especiales del Secretario General de Naciones Unidas. Así, tal nombramiento se realiza a los fines de indagar y vigilar en cuanto a los derechos humanos en países (mecanismos o mandatos por país) o sucesos relevantes acerca de vulneración de los derechos humanos en el mundo (mecanismos o mandatos temáticos).

Las funciones de los relatores especiales por mandatos temáticos se contemplan en la Resolución 2000/86 de la Comisión de Derechos Humanos de Naciones Unidas ${ }^{41}$ y consisten en las siguientes:

1. Realizar recomendaciones para prevenir las vulneraciones de los derechos humanos.

2. Realizar seguimientos y presentar en sus informes los avances gubernamentales realizados en los estudios realizados en la esfera de sus mandatos.

3. Seguir cooperando de forma cercana con los órganos creados en función de tratados y los relatores por Estados.

41 Resolución 2000/86 de 27 de abril de 2000. 
4. Insertar en sus informes la información procurada por los gobiernos acerca de medidas de seguimiento y sus observaciones sobre tales cuestiones, con especial énfasis con respecto a las eventualidades o avances, según sea cada caso.

5. Incluir de forma regular en sus informes datos descompuestos por sexo y evaluar las características y la incidencia de violaciones de derechos humanos incluidas por sus mandatos que se orienten principalmente contra la mujer, a fin de garantizar el resguardo de los derechos humanos del sexo femenino.

6. Evaluar además en sus informes los elementos caracterizadores y la incidencia de las violaciones de los derechos humanos que se orientaran especial o principalmente en perjuicio de los niños, o a las que los niños fueran específicamente vulnerables.

Ahora bien, con respecto a la materia específica del informe cuya obligatoriedad jurídica es aquí cuestionada, es menester indicar que las funciones anteriores se circunscriben al ámbito de actuación que por mandato de Naciones Unidas tiene el relator especial sobre la Promoción y Protección del Derecho a la Libertad de Opinión y Expresión. ${ }^{42}$ Por todo lo antes expuesto es que puede indicarse que básicamente los reportes realizados por los relatores especiales tienen tres implicaciones: a) Una de naturaleza descriptiva, pues narran y exponer hechos b) otra de naturaleza recomendatoria, ya que se encargan de emitir sugerencias para protección de derechos que abordan y, c) una implicación analítica, pues realizan el desglose de elementos condicionantes de los hechos observados.

Atendiendo a lo indicado supra, se afirma que efectivamente las fuentes informativas implicadas en la propagación de la noticia de que el informe del relator La Rue para el año 2011 constituía una declaración por parte de la ONU de que el acceso a Internet es un nuevo derecho humano en el plano internacional, han incurrido en un error tal vez por falta de profundización con un verdadero análisis jurídico, y con ello negligentemente se ha formado sobre este hecho una concepción indebida por aquellos individuos de la población que han tenido contacto con la noticia suministrada. El informe en cuestión básicamente establece las siguientes consideraciones con respecto a Internet ${ }^{43}$ :

a) Muy pocos, si acaso, aspectos desarrollados en las tecnologías de la información, han tenido tal efecto revolucionario como la creación de internet porque a diferencia de otros medios como la radio, la televisión o las publicaciones impresas basados en la información unidireccional, internet por el contrario constituye un medio interactivo.

b) Internet es un medio para que los individuos puedan ejercer su derecho a la libertad de expresión y opinión, tal como se garantiza en el artículo 19 de la Declaración Universal de Derechos Humanos y el Pacto Internacional de Derechos Civiles y Políticos.

c) El derecho a la libertad de expresión y de opinión es un derecho fundamental por su propia naturaleza, pero también un conductor (catalizador) a otros derechos, incluyendo derechos económicos, sociales y culturales como el derecho a la educación y el derecho a tomar parte en la vida cultural y disfrutar

42 En 1993, la Comisión sobre Derechos Humanos de Naciones Unidas estableció el mandato del relator especial sobre la Promoción y Protección del Derecho a la Libertad de Opinión y Expresión, y después de reemplazar a la Comisión sobre Derechos Humanos, el Consejo de Derechos Humanos decidió extenderlo por otros tres (3) años en su Resolución 7/36 de marzo 2008. Luego, el 24 de marzo de 2011, el Consejo de Derechos Humanos adoptó la Resolución 16/4 la cual extendió el mandato del relator especial por un período de tres (s) años. United Nations Human Righs - Office of the High Comissioner for Human Rights. Special Rapporteur on the promotion and protection of the right to freedom of opinion and expression (s.f.) 1.

43 La Rue (2011) pp.6-22. 
los beneficios del progreso científico y sus aplicaciones, así como también derechos civiles y políticos como los derechos a la libertad de asociación y la asamblea.

d) Internet como un medio por el cual el derecho a libertad de expresión y opinión puede materializarse, puede servir a este propósito solo si los Estados asumen su compromiso de desarrollar políticas efectivas para alcanzar el acceso universal a Internet.

En tal sentido, en las conclusiones de su informe considera el relator especial que los Estados deberían en consulta con su población, establecer políticas para procurar que el acceso a Internet esté disponible y sea sostenible, pues representa un canal para la concreción de derechos humanos, mientras que no se descarta tampoco el apoyo de los países desarrollados a aquellos en vías de desarrollo, para que estos últimos obtengan tecnología que les facilite un servicio universal que soporte Internet. Estas aseveraciones, son fortalecidas por La Rue con la ampliación que posteriormente realizó a su informe, dentro del marco de lo explanado por la Observación General número 34 CCPR/C/GC/34 del Comité de Derechos Humanos de Naciones Unidas, con referencia a la libertad de opinión y libertad de expresión, en la cual se indica que:

«Los Estados partes deberían tener en cuenta la medida en que la evolución de las tecnologías de la información y la comunicación, como Internet y los sistemas de difusión electrónica de la información en tecnología móvil, han cambiado sustancialmente las prácticas de la comunicación en todo el mundo. Ahora existe una red mundial en la que intercambiar ideas y opiniones, que no se basa necesariamente en la intermediación de los medios de comunicación de masas. Los Estados partes deberían tomar todas las medidas necesarias para fomentar la independencia de esos nuevos medios y asegurar el acceso a los mismos de los particulares.» ${ }^{44}$

Con lo cual, al ser las observaciones generales gestadas dentro del seno de la ONU un referente para la comprensión del alcance de los Derechos Humanos, se destaca la importancia de la afirmación realizada en la cita anterior, pues en este texto se sostiene que Internet (con los mecanismos de difusión electrónica) ha representado un cambio en los antiguos paradigmas admitidos en torno a los sistemas de comunicación. También se concluye en el informe que debe recomendarse a los Estados que cuenten con una sólida infraestructura de Internet, la promoción de su uso significativo sin exclusión de sectores poblacionales, e incluso, que se admita el aprendizaje por módulos online en el contenido curricular escolar, de manera que se fomenten las habilidades para la protección y el respeto en la red.

\section{El informe de la OSCE: libertad de expresión e Internet}

Observando todas las circunstancias anteriormente expuestas, así como las normas y los hechos a los cuales hace alusión el relator especial La Rue en su informe, debe indicarse que «si bien no dan pie para afirmar que el acceso a internet es un derecho fundamental vinculante en el plano internacional», al interconectarse con derechos básicos de la personalidad, ha implicado la apertura de una puerta para su potencial y pleno reconocimiento. Incluso de tal importancia ha resultado esta relatoría, que sirvió como punto referencial al informe generado por comisión de la Oficina del Representante para la Libertad de los Medios de Comunicación de la Organización para la Seguridad y Cooperación en Europa (Organization for Security and Co-operation in Europe - OSCE), siendo encargado en la estructuración del mismo, el

44 Comité de Derechos Humanos (2011) p.1. 
experto turco en Internet y docente universitario de Derecho Yaman Akdeniz. En dicho informe, que se signó bajo el nombre Libertad de Expresión en la Internet - Estudio de las Previsiones y Prácticas Legales Relativas a la Libertad de Expresión, El Libre Flujo de Información y el Pluralismo Mediático sobre la Internet en los Estados Participantes de la OSCE (Report Freedom of Expression on the Internet - Study of Legal Provisions and Practices Related to Freedom of Expression, the Free Flow of Information and Media Pluralism on the Internet in OSCE Participating States) ${ }^{45}$, se denomina a un apartado como "Acceso a Internet - Un Derecho Fundamental.»

De acuerdo con el objeto del informe, se estableció que mientras por una parte ciertos países y organizaciones internacionales, en específico las Naciones Unidas están considerando reconocer el acceso a Internet en su carácter inherente al derecho a la libertad de expresión, y como tal tomarlo como un derecho fundamental y universal, un número de gobiernos estima adoptar medidas de bloqueo de contenido y acceso. Así a todo este respecto, se concluye con esta parte del reporte que Internet es en una herramienta indispensable para que la gente tome parte en el discurso cultural, político y social y por lo tanto, todo mundo debería poseer el derecho de participar en la sociedad de la información y los Estados tener la responsabilidad de asegurar a sus ciudadanos el acceso a Internet. Las políticas de acceso a la red deberían alinearse con el artículo 19 de la Declaración Universal de los Derechos Humanos, entre otros instrumentos jurídicos de esta naturaleza.

\section{Otros documentos relativos a la protección de Internet en el marco de los Derechos Humanos}

Resulta oportuno indicar que con posterioridad a la estructuración del referido informe de La Rue al cual se le ha dado especial trascendencia por haber desatado la matriz de opinión de que ya internacionalmente se declaraba internet como derecho humano, el día 01 de julio de 2016 fue aprobada la Resolución 32/13 en el Consejo de Derechos Humanos ${ }^{46}$ y aunque ella no tiene un carácter vinculante (es un texto de soft law), resulta importante porque en la misma se asume que en Internet se deben respetar los mismos derechos fundamentales de los cuales se goza en el mundo tangible, especialmente el derecho a la libertad de expresión, la educación a través de la alfabetización digital y el deber de que los Estados aseguren el acceso a esta red de redes. Es un trascendental documento que sirve para soportar que Internet es un agente catalizador para impulsar los derechos naturales.

Por otra parte debe destacarse que en el año 2019 se adoptó la Declaración conjunta del vigésimo aniversario: Desafios para la libertad de expresión en la próxima década, la cual fue suscrita por el relator especial de las Naciones Unidas (ONU) para la Libertad de Opinión y de Expresión, la Representante de la Organización para la Seguridad y la Cooperación en Europa (OSCE), el relator rspecial de la Organización de Estados

45 El reporte presenta las conclusiones de la primera investigación comprensiva sobre la regulación de contenidos en Internet en la región OSCE, siendo que un reporte preliminar fue preparado y publicado en vista de la conferencia de revisión OSCE y la Cumbre OSCE Astana 2010. La información contenida en este reporte está basada en datos recibidos de los Estados OSCE participantes así como fuentes confiables, en respuesta a un cuestionario enviado el 23 de septiembre 2010. Como la mayoría de las respuestas se recibieron recientemente en la elaboración del informe y como la legislación y las prácticas cambian, el estudio y las secciones por país de la parte II permaneció abierto para mejoras y adiciones en los meses subsiguientes a la publicación del reporte. Entre los Estados que para el momento tenían previsiones relativas al acceso, un número de respuestas establecieron que el derecho de acceso a Internet es un derecho interconectado con el derecho de acceso a la información y comunicación, protegidos por las Constituciones Estatales. Esto incluye que todo el mundo tiene derecho a participar en la sociedad de la información y el Estado tiene una responsabilidad de asistir en el avance de ella (en este bloque se encuentran Chipre, Estonia, Georgia, Grecia, Portugal, Rusia y Ucrania). En algunos Estados, el acceso a internet está provisto por leyes específicas, usualmente dentro de leyes de acceso universal o regulaciones. Akdeniz (2012) pp.1- 35.

46. Resolución 32/13 de 1 de julio de 2016. 
Americanos (OEA) para la Libertad de Expresión y el Relator Especial sobre Libertad de Expresión y Acceso a la Información de la Comisión Africana de Derechos Humanos y de los Pueblos (CADHP), ampliándose de esta forma la visión internacional de las consideraciones sobre los derechos humanos e internet. $^{47}$

Básicamente, en la declaración se tratan puntos como aspectos generales sobre el tema, la generación de un ambiente que permita la libertad de expresión, la consolidación de una Internet abierta y la explicación sobre como el control privado puede amenazar la libertad de expresión pero es en extremo importante este documento cuando apunta que se invita a los Estados a «reconocer el derecho al acceso y el uso de Internet como un derecho humano», ${ }^{48}$ con lo cual se evidencia que aún en estos momentos se lucha por la acepción de esta prerrogativa fundamental en declaraciones jurídicas formales de manera generalizada en los distintos países, y el panorama parece incierto a futuro en cuanto al momento en el cual existirá una acuerdo definitivo en torno a tal cuestión, pero no por eso significa que la discusión sobre este tópico deje de ser activa.

Todo esto se concatena con la Resolución del Consejo de Derechos Humanos de Naciones Unidas en la resolución del del 29 de junio del 2012 sobre promoción, protección y difusión de los derechos humanos en Internet. En ella ya se indica: «(...) los derechos de las personas también deben estar protegidos en Internet, en particular la libertad de expresión, que es aplicable sin consideración de fronteras y por cualquier procedimiento que se elija, de conformidad con el artículo 19 de la Declaración Universal de Derechos Humanos y del Pacto Internacional de Derechos Civiles y Políticos; 2. Reconoce la naturaleza mundial y abierta de Internet como fuerza impulsora de la aceleración de los progresos hacia el desarrollo en sus distintas formas; 3. Exhorta a los Estados a que promuevan y faciliten el acceso a Internet y la cooperación internacional encaminada al desarrollo de los medios de comunicación y los servicios de información y comunicación en todos los países» ${ }^{49}$

Por lo ya expresado, es que no resulta extraño que Dunja Mijatović (citada por Criado como representante para la Libertad de los Medios de Comunicación de la OSCE en 2011), haya sostenido que "Internet debe seguir siendo libre y el acceso debe ser considerado un derecho humano». ${ }^{50}$ Es pues este grupo de documentos la representación de una reafirmación no vinculante de entes de la comunidad internacional en el marco del Derecho Internacional de los Derechos Humanos por la cual se sostiene que Internet debería ser protegida de manera obligatoria en los Estados. Esta última acepción existe solamente por ahora en la esfera interna de países a través de fuentes formales del Derecho como jurisprudencia y normas jurídicas cuyos ejemplos se han indicado a lo largo de este artículo y que se han adaptado también en ellos a tenor de otros derechos contenidos en tratados de derechos humanos (como el Pacto Internacional de Derechos Civiles y Políticos, solo por mencionar uno), los cuales deben protegerse por los Estados signatarios como parte de sus obligaciones.

\footnotetext{
47 Ya para el año 2011 había sido suscrita una Declaración Conjunta sobre Libertad de Expresión e Internet por los mismos despachos, en la cual se estipuló que los Estados deben promover el servicio de internet en aras de la materialización efectiva de la libertad de expresión, esto sin descontar que con la red se aseguran otras prerrogativas como el derecho a la educación, el derecho a la salud, el derecho al trabajo, el derecho de reunión y asociación, así como el derecho a elecciones libres. Botero Et al (2011) p.1.

48 Desir Et al (2019) p.1.

49 Resolución A/HRC/20/L.13 del 29 de junio del 2012.

50 Criado (2011) p.1.
} 


\section{Reflexiones finales}

Aceptar cambios otorga al Derecho un rostro diferente al clásicamente conocido entre juristas. Dichas metamorfosis deben justificarse y poseer un asidero lógico e imparcial teniendo en cuenta las necesidades sociales. Por ello, sostiene Antonio Osuna Fernández-Lago que: «El conglomerado de exigencias y enunciados jurídicos que denominamos como derechos humanos no es algo homogéneo ni inalterable históricamente, sino algo fluido y no expresado siempre en los mismos términos, ya que han sido enunciados desde una concepción determinada de lo que es el ser humano, de lo que es la organización política de la sociedad y de lo que es el derecho. No hay un catálogo inalterable de derechos humanos, como no hay una única concepción doctrinal que los proponga» ${ }^{51}$

Como ya se ha referido, Internet representa un vehículo para la manifestación activa y material de derechos fundamentales tan importantes como el derecho a la libertad de expresión, el derecho a la libertad de la información, el derecho a la igualdad o el derecho al libre desenvolvimiento de la personalidad, entre otros, por lo que muy bien pudiera pensarse que resultaría innecesaria la tutela especial de esa fuente de comunicación como un interés especialmente relevante si ya los otros derechos han sido protegidos. Sin embargo, la red es hoy por hoy, un instrumento que debe estudiarse de forma minuciosa desde el punto de vista del Derecho debido a las consecuencias que genera su uso, aparte que como ya se indicó a diferencia de los panfletos, los periódicos, las revistas o la televisión, es un medio para la información y expresión que tiene alcance más global, interactivo y multidireccional, pues permite interconexión entre personas en todo el mundo.

Así, quien escribe estas líneas estima que si bien es cierto que el acceso a la red de redes no ha sido aún declarado como un derecho humano en el contexto formal normativo internacional (a diferencia de ciertos países y sus leyes internas), no puede negarse la posibilidad de que en un futuro pueda llegar a ser considerado como tal. Tampoco puede dejar de considerarse que una de las características de los derechos humanos es su virtud de permanencia en el tiempo y por eso puede ser que en los subsiguientes años surja una herramienta con las mismas utilidades que resulte más poderosa que Internet, pero tomando en cuenta que hasta ahora no ocurre esto, habrá que tener apertura como juristas en cuanto a que al igual que el derecho al agua potable o de los derechos medioambientales, lo mismo podría ocurrir con el acceso a Internet y su internacionalización.

Ahora bien, independientemente de lo antes planteado toda persona está en el derecho de sostener la postura que mejor le parezca y por ello el autor de este artículo considera que: a) La noción de Derecho Fundamental de Acceso Internet existe en el plano doctrinal y jurídico interno de algunos Estados b) internacionalmente aún no se reconoce como hard law la existencia de este derecho y c) no se niega la posibilidad de que a futuro en la esfera interestatal llegue a reconocerse por instrumentos de Derecho sólidos, porque nadie sabe lo que depara el futuro, el mundo jurídico es dinámico y así como se encuentra condicionado por fenómenos sociales, también lo está por la historia humana.

51 Osuna (2001) p.19. 


\section{Bibliografía Citada}

\section{Artículos y libros}

Aguado, César y Aragón Reyes, Manuel (2011): Derechos Fundamentales y su Protección (Navarra, Thomson Reuters), Tomo III.

Akdeniz, Yaman (2012): «Report: Freedom of Expression on the Internet, Organization for Security and Co-Operation in Europe« Disponible en https://www.osce.org/fom/105522?download=true [fecha de consulta: 15.01.2020].

Alto Comisionado de las Naciones Unidas para los Derechos Humanos (2000): Los Derechos Humanos y los Procedimientos Temáticos. Resolución de la Comisión de Derechos Humanos 2000/86. 2000. Disponible en: ap.ohchr.org, documents, CHR, resolutions, E-CN_4-RES-2000-86. Consulta: 21 de enero de 2019.

Amnistía Internacional (s.f.): «Los Derechos Humanos, Teorías y Definiciones« Disponible en http:// www.amnistiacatalunya.org/edu/2/dh/dh-der-defin1-cast.html [fecha de consulta: 20.01. 2020].

Arango, Rodolfo (2008): «La Objetividad de los Derechos Fundamentales», (colaborador) en Derechos Humanos como Limite a la Democracia (Bogotá, Editorial Norma) pp. 1 - 3.

BBC Mundo, (2011): «La Banda Ancha es la Nueva División entre Naciones« Disponible en http://www. bbc.co.uk/mundo/noticias/2011/09/110915_banda_ancha_brecha_cch.shtml [Fecha de consulta: 10.01.2020].

Baldassare, Pastore (2017): «Soft Law y la Teoría de las Fuentes del Derecho». Disponible en https:// editorial.ucatolica.edu.co [Fecha de consulta: 17.05.2020].

Carbonell, Miguel y Carpizo, Jorge (2000): Derecho a la Información y Derechos Humanos (México, Universidad Nacional Autónoma de México).

CNN (2011): «El acceso a Internet, un derecho humano según la ONU». Disponible en https:// cnnespanol.cnn.com/2011/06/09/el-acceso-a-internet-un-derecho-humano-segun-la-onu/ [Fecha de consulta: 03.01. 2020].

Comité de Derechos Humanos de Naciones Unidas (2011): «Observación General núm. 34 CCPR/C/GC/34». Disponible en https://conf-dts1.unog.ch/1\%20SPA/Tradutek/Derechos_ hum_Base/CCPR/00_2_obs_grales_Cte\%20DerHum\%20\%5BCCPR\%5D.html [Fecha de consulta:20.01.2020].

Criado, Miguel. (2011). Solo un tercio de los países occidentales considera internet como un derecho. Disponible en: https:/www.cuartopoder.es/innovacion/2011/07/16/solo-un-tercio-de-los-paisesoccidentales-considera-internet-como-un-derecho/ [Fecha de consulta 17.05.2020].

De Miguel Asensio, Pedro (2001): «El Derecho Internacional Privado Ante la Globalización», (colaborador) en Anuario Español de Derecho Internacional Privado (Madrid, Iprolex, tomo I) pp. 37 - 87.

Diez de Velasco, Manuel (2009): Instituciones de Derecho Internacional Público (Madrid, Tecnos, decimoséptima edición).

El Mundo (2011): «Naciones Unidas Declara el Acceso a Internet como un Derecho Humano». Disponible en http://www.elmundo.es/elmundo/2011/06/09/navegante/1307619252.html [fecha de consulta: 20.012020].

La Rue, Frank (2011): "General Assembly: Report of the Special Rapporteur on the Promotion and Protection of the Right of Freedom of Opinion and Expression, informe A/HRC/17/27 Human Rights Council». Disponible en https://www.acnur.org/fileadmin/Documentos/BDL/2015/10048. pdf [Fecha de consulta: 10.01.2020]. 
La Rue, Frank - Asamblea General (2011): «Promoción y Protección del Derecho a la Libertad de Opinión y de Expresión». Disponible en: https://www.ohchr.org/Documents/Issues/Opinion/A.66.290.pdf [Fecha de consulta: 11.01.2020].

Organización de Naciones Unidas - Oficina del Alto Comisionado para los Derechos Humanos (s.f.). "¿Qué son los Derechos Humanos?». Disponible en http://www.ohchr.org/SP/Issues/Pages/ WhatareHumanRights.aspx [Fecha de consulta: 22.01.2020].

Ortega, Jesús (2004): Sociedad de la Información y Derechos Humanos de Cuarta Generación. Un Desafio Inmediato para el Derecho Constitucional, Memoria del Congreso Internacional de Culturas y Sistemas Comparados, (México, Universidad Nacional Autónoma de México).

Osuna Fernández-Lago, Antonio (2001): Teoría de los Derechos Humanos. Conocer para Practicar, (Salamanca, Editorial San Esteban).

Rivero, Raúl (2002): «Evolución de ARPANET/Internet». Disponible en https://www.elmundo.es/imasd/ docs/cursos/masterperiodismo/2002/rivero-master01-usa.html [Fecha de consulta: 08.01.2020].

United Nations Human Righs - Office of the High Comissioner for Human Rights (s.f.): «Special Rapporteur on the promotion and protection of the right to reedom of opinion and expression». Disponible en: http://www.ohchr.org/EN/Issues/FreedomOpinion/Pages/OpinionIndex.aspx [Fecha de consulta: 18.01.2020].

VV.AA. (2007): Derecho Internacional, (Valencia - España, Tirant Lo Blanch).

VV.AA. (2008): Manual de Derecho Constitucional, (Madrid, Tecnos, tercera edición).

VV.AA. (2011): Declaración conjunta sobre Libertad de Expresión e internet. Disponible en http://www. oas.org/es/cidh/expresion/showarticle.asp?artID=849\&lID=2 [Fecha de consulta: 17.05.2020].

VV.AA. (2019): Declaración conjunta vigésimo aniversario: «Desafíos para la libertad de expresión en la próxima década». Disponible en http://www.oas.org/es/cidh/expresion/showarticle. asp?artID $=1146 \& \mathrm{IID}=2$ [Fecha de Consulta: 16.01.2020].

\section{Normas citadas}

Act 393/2003 (2003) Communications Market Act de Finlandia.

Constitución de la República de Grecia (09/06/1975).

Convención Americana sobre Derechos Humanos (22/11/1969).

Convenio para la Protección de los Derechos Humanos y las Libertades Fundamentales (04/09/1950).

Declaración de los Derechos del Hombre y del Ciudadano (26/08/1789).

Observación General núm. 34 CCPR/C/GC/34del Comité de Derechos Humanos de Naciones Unidas $(12 / 09 / 2011)$.

Resolución 2106 de la Asamblea General de Naciones Unidas (21/12/1965) Convención Internacional sobre la Eliminación de todas las Formas de Discriminación Racial.

Resolución 2200 A (XXI) de la Asamblea General de Naciones Unidas (16/12/1966) Pacto Internacional de Derechos Civiles y Políticos.

Resolución 2000/86 de la Comisión de Derechos Humanos (27/04/2000) Los Derechos Humanos y los Procedimientos Temáticos.

Resolución 34/180 de la Asamblea General de Naciones Unidas (18/12/1979) Convención sobre la Eliminación de todas las Formas de Discriminación contra la Mujer.

Resolución 32/13 del Consejo de Derechos Humanos de Naciones Unidas (01/07/2016). 
Resolución A/RES/64/292 de la Asamblea General de Naciones Unidas (28/07/2010) Resolución aprobada por la Asamblea General sobre el derecho humano al agua y al saneamiento.

Resolución A/HRC/20/L.13 del Consejo de Derechos Humanos de Naciones Unidas (29/06/2012) sobre promoción, protección y difusión de los derechos humanos en internet.

Telecommunications Act de Estonia (09.02.2000).

\section{Jurisprudencia citada}

Asociación de Comerciantes de San Ramón y Figari con Municipalidad distrital de Miraflores (2007): Tribunal Constitucional del Perú, 22 de junio de 2007 (demanda de inconstitucionalidad). Disponible en: https://www.tc.gob.pe/jurisprudencia/2007/00007-2006-AI.html. Fecha de consulta: 17 de enero de 2020.

Diputados con Ley por la que se favorece la difusión y la protección de la creación en internet (2009): Consejo Constitucional francés, 10 de junio de 2009 (impugnación de ley). Disponible en: https:// www.conseil-constitutionnel.fr/sites/default/files/as/root/bank_mm/espagnol/es2009_580dc.pdf. Fecha de consulta: 17 de enero de 2020.

Recurrente con Instituto Costarricense de Electricidad (2010): Sala Constitucional de la Corte Suprema de Justicia de Costa Rica, 18 de junio de 2010 (recurso de amparo). Disponible en: http://proledi. ucr.ac.cr/wp-content/uploads/2018/10/CUADERNILLO-04-El-derecho-de-acceso-a-Internet-yla-Libertad-de-Expresio\%CC\%81n.pdf. Fecha de consulta: 18 de enero de 2020.

Recurrentes con Ministerio de Ambiente, Energía y Telecomunicaciones, Ministerio de la Presidencia (2010): Sala Constitucional de la Corte Suprema de Costa Rica, 30 de julio de 2010 (recurso de amparo). Disponible en: http://www.litigioscomplejos.com/sentencias/costa-rica/12790.pdf. 